\title{
SISTEM INFORMASI PEMANTAUAN PENJUALAN BERBASIS WEB PADA PT. GMF AERO ASIA (GARUDA INDONESIA GROUP) UNIT MARKETING \& BUSINESS DEVELOPMENT
}

\author{
Bayu Pramono*1, Pepen Aandrian Syah ${ }^{2}$, Al Anwar ${ }^{3}$ \\ 1,2,3 Program Studi Sistem Informasi Universitas Raharja \\ E-mail: ${ }^{* 1}$ bayupramono@raharja.info, ${ }^{2}$ pepen@raharja.info ${ }_{2}{ }^{3}$ al.anwar@raharja.info
}

\begin{abstract}
Abstrak
Sistem informasi pemantauan penjualan berguna untuk mengontrol jalannya penjualan pada suatu perusahaan dan untuk mengetahui laporan pendapatan perusahaan. Dalam penyusunan laporan pendapatan dibutuhkan suatu sistem yang terkomputerisasi, sehingga setiap proses pembuatan laporan pendapatan dapat berjalan secara efektif dan efisien serta di imbangi dengan sumber daya manusia yang memadai. Tetapi pada implementasinya, PT. GMF Aero Asia (Garuda Indonesia Group) unit Marketing \& Business Development, belum memiliki sistem yang mencakup seluruh kegiatan. Salah satunya pada G.M TPR dalam pembuatan laporan pendapatan masih manual dengan cara menggunakan Ms. Excel dan media yang digunakan masih sangat besar kemungkinan terjadinya human error sehingga dibutuhkan suatu sistem pemantauan penjualan yang dapat menghasilkan laporan pendapatan yang lebih akurat dan efektif dalam proses pembuatan laporan pendapatan. Penelitian ini menggunakan metode analisa Rantai Nilai (Value Chain), elisitasi untuk kebutuhan suatu sistem, serta analisa sistem dengan menggunakan pemodelan Unified Modelling Language (UML) untuk menggambarkan secara visualisasi, yang selanjutnya dari analisa tersebut diimplementasikan dengan bahasa pemrograman PHP dengan sebuah basis data MySQL-Server sebagai database yang digunakan. Sistem pemantauan penjualan ini, dapat mempermudah G.M TPR untuk menghasilkan laporan pendapatan yang akurat dengan waktu yang cepat, sehingga dapat menciptakan kinerja yang efektif dan efisien.
\end{abstract}

Kata Kunci : Laporan Pendapatan, Rencana Penjualan, Pemantauan Penjualan

\begin{abstract}
Sales monitoring information system is useful to control the course of sales in a company and to find out the company's income reports. In compiling income reports a computerized system is needed, so that each process of making income reports can run effectively and efficiently and balanced with adequate human resources. But in its implementation, PT. GMF Aero Asia (Garuda Indonesia Group) Marketing \& Business Development unit, does not yet have a system that covers all activities. One of them is on G. M TPR in making income statements is still manual by using Ms. Excel and the media used are still very likely to cause human error, so we need a sales monitoring system that can produce income reports that are more accurate and effective in the process of making income reports. This study uses a Value Chain analysis method, elicitation for the needs of a system, and system analysis using Unified Modeling Language (UML) modeling to illustrate visualization, which then from the analysis is implemented with the PHP programming language with a MySQL database Server as a database used. This sales monitoring system, can make it easier for G. TPR to produce accurate income reports with a fast time, so as to create effective and efficient performance.
\end{abstract}

Keywords: Revenue Report, Sales Plan, Sales Monitoring 


\section{PENDAHULUAN}

Sebuah sistem pemantauan penjualan adalah sistem yang mencatat aktivitas dan memberi informasi yang berguna. Sistem pemantauan penjualan memiliki banyak fitur yang memungkinkan setiap pengguna untuk menangkap data tentang aktivitas penjualan, dapat melihat sampai mana proses negosiasi yang sedang berlangsung sehingga nantinya menghasilkan laporan pendapatan.

Dorongan paling utama untuk membuat sistem informasi pemantauan penjualan adalah sebagai pendukung dalam mendefinisikan sudah sampai mana pembuatan laporan pendapatan yang dilakukan oleh setiap Account Manager \& Sales.

Pembuatan sistem informasi pemantauan penjualan sangat memerlukan dukungan dari setiap organisasi yang ada karena perlu penyesuaian dari segi manusia dan sumber daya lain yang tersedia pada perusahaan. Sebelum tahap pembuatan dan implementasi dilakukan perlu dilakukann tahapan rancangan yang memerlukan banyak dukungan dari pihak manajemen organisasi.

Dalam pelaksanaan pengolahan data pemantauan penjualan pada Unit Marketing \& Bussiness Development, sebenernya sudah menggunakan alat bantu semi terkomputerisasi yaitu dengan cara di input pada Microsoft excel, sehinnga dalam pembuatan laporan pendapatan yang akurat membutuhkan waktu lama, sehingga diperlukan sebuah analisa terhadap sistem yang berjalan tersebut untuk mencapai terciptanya sistem yang dapat menunjang kinerja pegawai, sehingga kualitas dari laporan pendapatan yang dihasilkan lebih baik.

Selain itu laporan pendapatan merupakan salah satu hal yang harus dihasilkan secara cepat, tepat dan akurat sehingga diperlukan pengelolaan data yang lebih baik. Karena laporan pendapatan merupakan unsur yang penting dalam pengawasan serta pengendalian kegiatan suatu organisasi, dan melalui laporan pendapatan kita dapat mengetahui berada dalam posisi aman atau tidak kehidupan organisasi dapat berlangsung. Sehingga memudahkan SVP Marketing \& Bussiness Development dan pimpinan dalam pembuatan keputusan yang rasional mengenai alokasi sumber daya organisasi.

\section{METODE PENELITIAN}

Metode penelitian yang digunakan pada penelitian ini adalah:

2.1 Metode Pengumpulan Data

Dalam pengumpulan data, penulis menggunakan 3 (tiga) pendekatan yaitu sebagai berikut :

a. Metode Observasi (Observasi Research)

Pada metode ini peneliti melakukan analisa terhadap suatu masalah yang ada dengan cara mengamati sumber, pengumpulan dan pengolahan data di bagian pendapatan Unit Marketing \& Bussiness Development yang berhubungan dengan sistem pengolahan data laporan pendapatan, baik berupa dokumen transaksi, catatan-catatan, maupun laporan.

b. Metode Wawancara (Interview Research)

Metode ini dilakukan dengan cara, peneliti melakukan pengumpulan data melalui tanya jawab langsung dengan stakeholder yaitu dengan Ibu Wiwin sebagai bendahara umum dan Ibu Reni sebagai Auditor Ekternal Unit Marketing \& Bussiness Development, yang berhubungan dengan sistem pengolahan data laporan pendapatan dan memahami semua hal yang akan diteliti sesuai dengan tujuan penelitian.

c. Metode Study Pustaka (Library Research)

Metode study kepustakaan dilakukan untuk menunjang metode wawancara dan observasi yang telah dilakukan oleh peneliti. Pengumpulan informasi dan data yang dilakukan dengan cara membaca dan mempelajari beberapa buku yang berhubungan 
dengan teori yang dibahas dalam jurnal ini, melalui sumber-sumber dari kepustakaan dan internet.

\subsection{Metode Analisa Data}

a. Setelah melakukan proses pengumpulan data, data yang sudah diperoleh dapat diolah dan dianalisa oleh peneliti. Dalam melakukan analisa sistem pengolahan data laporan pendapatan pada Unit Marketing \& Bussiness Development, disini peneliti menggunakan metode analisa sistem yang dilakukan yaitu, analisa Value Chain.

b. Analisa Value Chain digunakan peneliti untuk menganalisa agar meningkatkan kualitas dan kuantitas yang harus dicapai dengan sebuah konsep yang matang, perlunya analisa value chain sebagai aktivitas pendukung yang membantu organisasi secara keseluruhan dengan menyediakan dukungan yang diperlukan bagi berlangsungnya aktivitas yang dilakukan secara berkelanjutan.

c. Selain itu peneliti menggunakan Unified Modeling Language (UML) sebagai salah satu alat bantu untuk membuat model analisa secara visual yang dapat digunakan dalam bahasa pemograman yang berorientasi objek. Unified Modeling Language terdiri dari beberapa diagram yang saling berkaitan satau sama lain.

d. Kemudian peneliti menggunakan metode Elisitasi untuk mengumpulkan dan menyeleksi kebutuhan sistem yang diharapkan stakeholder. Elisitasi merupakan rancangan sistem yang diusulkan sesuai dengan keinginan atau kebutuhkan user.

\subsection{Metode Perancangan}

Perancangan sistem menggunakan metode Unified Modelling Language (UML) yang akan dituangkan dalam tahap : pembuatan Use Case Diagram, Sequence Diagram, Activity Diagram, dan Class Diagram serta penjabaran rancangan basis data dan spesifikasi data yang ada pada sistem, dengan menggunakan beberapa software dalam perancangannya yaitu : PHP MyAdmin, Apache, MYSQL, Visual Paradigma, dan Chrome.

\subsection{Pengacuan Pustaka}

Berikut penelitian yang telah dilakukan dan memiliki keterkaitan dengan penelitian yang akan dibahas:

1. Penelitian yang dilakukan oleh Benny Prawiranegara dalam jurnal ilmiah edukasi Vol, 5 No.2, November 2017, ISSN 2580-8818 dengan judul Analisa Audit Operasional Dalam Meningkatkan Efektivitas Pengendalian Intern Penjualan Pada PD. ACB Banjarsari. Kelebihannya adalah dapat mengetahui apakah prosedur penjualan sudah dapat beroperasi dengan efektif dan efisien dan kekurangannya dari analisa tersebut adalah masih ada nya penyimpangan yang terjadi dalam aktivitas penjualan perusahaan. Metodologi yang digunakan adalah metode deskriptif untuk mendapatkan data dengan tujuan dan kegunaan tertentu.

2. Penelitian yang dilakukan oleh Gerald Lumempouw, Ventje Hat dan Anneke Wangkar dalam jurnal berkala ilmiah efisiensi, Vol. 15 No.04 Tahun 2015, dengan judul Evaluasi Sistem Pengendalian Intern Terhadap Penjualan Kredit Pada PT. Sinar Pure Foods Internasional. Kelebihannya adalah dapat mengevaluasi terhadap sistem pengendalian intern penjualan kredit pada PT Sinar Pure Foods Internasional dan kekurangannya adalah belum terotoritasi kepada pihak yang berwenan. Metode analisa data yang digunakan adalah metode deskriptif adalah mempelajari prosedur pemberian kredit yang berlaku pada PT. Sinar Purefoods Internasional.

3. Penelitian yang dilakukan oleh Ari Prasetyo Suwandi dalam jurnal J-INTECH Vol. 04 No. 01 Tahun 2016, ISSN 2303-1425, dengan judul Sistem Informasi Pemantauan Kinerja Sales Memanfaatkan Monitoring Geofencing dan Teknologi Cloud Message Berbasis Mobile. Kelebihannya adalah dapat memantau dan meninjau pegawai dalam hal ini adalah sales ketika berada dilapangan dan dalam waktu kerja dan kekurangannya adalah dalam 
perhitungan laporan pendapatan dapat disusun berdasarkan transaksi yang ada masih kurang baik dan belum lengkap. Metodologi yang digunakan adalah UML (Unified Modelling Language) adalah metode analisa dan desain yang berorientasi objek.

\section{HASIL DAN PEMBAHASAN}

Dalam penelitian ini, akan dijelaskan mengenai rancangan sistem pemantauan penjualan berbasis web pada PT. Gmf Aero Asia (garuda indonesia group) unit marketing \& business development. Dalam penelitian ini, penulis merancang sistem usulan pemantauan penjualan berbasis website yang dapat merubah proses pemantauan penjualan, pembuatan rencana penjualan dan laporan pendapatan. Serta laporan yang dihasilkan akan lebih efektif. Dalam rancangan ini, proses peng-input-an data dilakukan dengan rencana penjualan data yang ada akan dipantau oleh G.M TPR dan di oleh Account Manager \& Sales dan para G.M Key Account update secara terus menerus hingga mendapatkan suatu hasil yang diinginkan. Setiap sistem pasti memiliki batasan yang memisahkan antara suatu sistem dengan hal yang ada pada lingkungan luarnya. Sesuai dengan permasalahan yang diambil oleh peneliti, bahwa hal yang akan dibahas adalah mengenai permasalahaan sistem pemantauan penjualan pada PT. GMF Aero Asia (Garuda Indonesia Group). Permasalahan yang diambil yaitu mengenai Rencana Penjualan, Laporan Pendapatan, Target Perusahaan, Target Account Manager \& Sales dan G.M Key Account dan Kenaikan Level Rencana Penjualan.

Dalam rancangan sistem yang diusulkan yang dapat dijelaskan pada use case diagram, activity diagram, sequence diagram dan class diagram dengan menggunakan Visual Paradigma for UML 6.4 Enterprise Edition.

\section{Analisis Rantai Nilai}

Dalam penelitian ini, peneliti menggunakan metode analisis Rantai nilai (Value Chain) merupakan metode yang menggambarkan seluruh aktifitas didalam perusahaan dalam sebuah nilai. Aktifitas yang didalamnya menjadikan suatu nilai berharga bagi pelanggan untuk dapat memahami keunggulan kompetitatif perusahaan terhadap keunggulan dari perusahaan lain, dengan Metode Rantai Nilai (Value Chain) dapat membantu menganalisa aktifitas yang ada dalam kinerja keuangan di Unit Marketing \& Business Development PT. GMF Aero Asia (Garuda Indones Group), yang dapat meminimalisir kesalahan dalam kinerja seperti pembuatan laporan keuangan salah satunya. Berikut ini merupakan gambar grafik penjelasan mengenai aktifitas yang dilakukan, yaitu : 


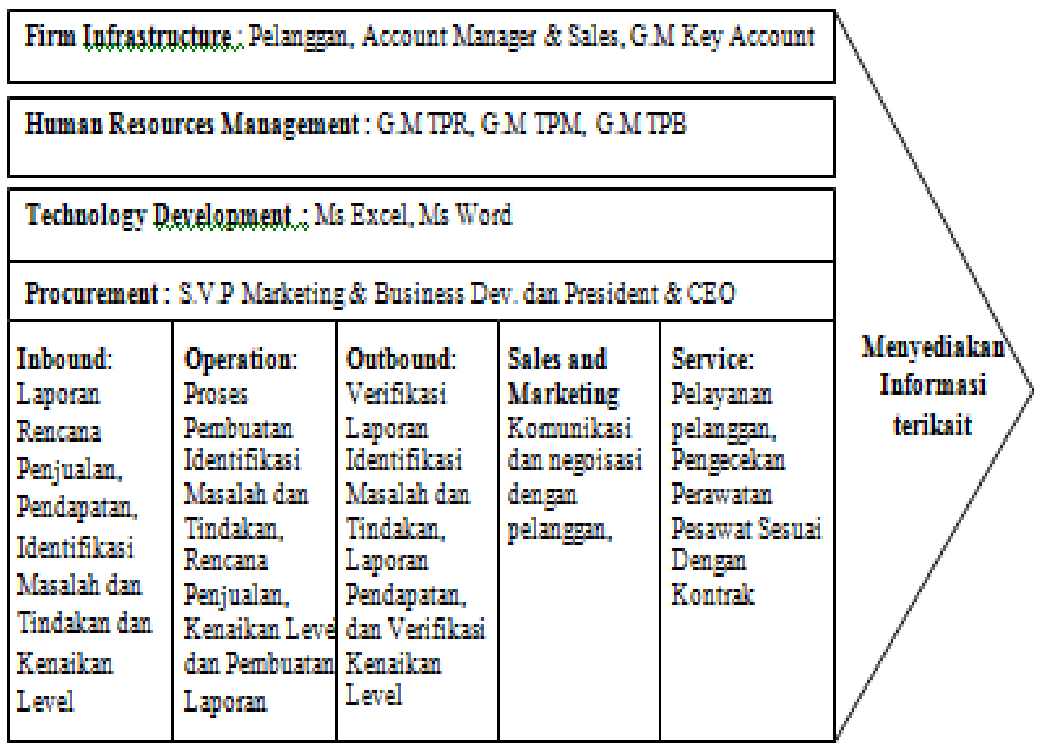

Gambar 1. Analisis Rantai Nilai

\section{Use Case Diagram Sistem Informasi pemantaun penjualan}

Gambar dibawah ini adalah Use Case Diagram untuk menggambarkan secara umum Sistem pemantauan penjualan saat ini yang menggambarkan alur sistem dengan use case dan aktoraktor (user) yang terlibat. Berdasarkan diagram tersebut, terdapat 4 actor dalam proses kegiatan yang berjalan, yaitu G,M TPR, Account Manager \& Sales, G.M Key Account dan President \& CEO. Dan juga terdapat 4 use case kegiatan oleh actor, yaitu Rencana Penjualan, Laporan Pendapatan, Target Account Manager \& Sales dan G.M Key Account dan kenaikan level rencana penjualan. 
ISSN : $2356-5195$

Online ISSN: 2654 - 8704

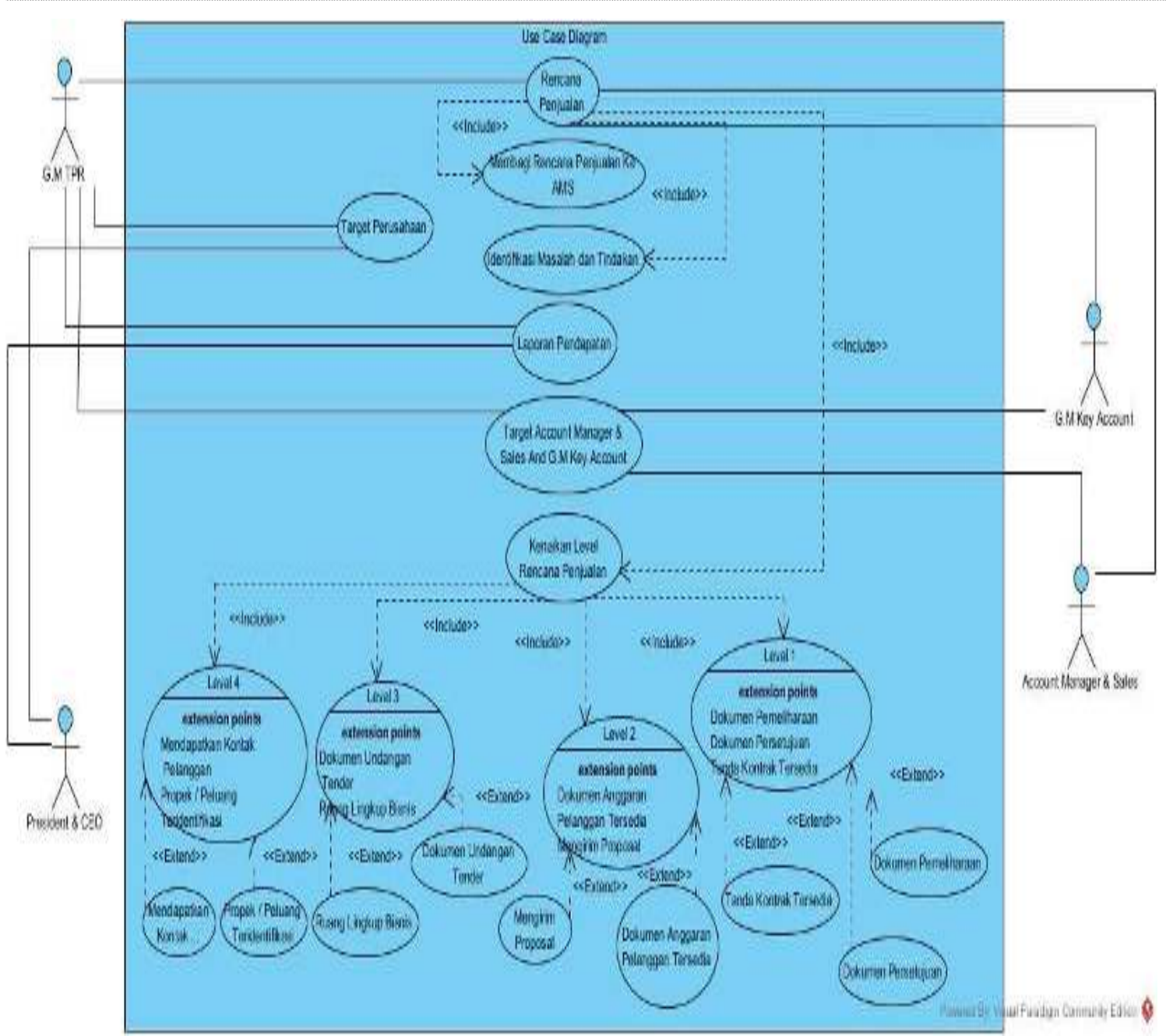

Gambar 2. Use Case diagram Sistem Informasi pemantaun penjualan

\section{RANCANGAN SISTEM}

Untuk mengatasi masalah yang ada saat ini, dibutuhkan rancangan Sistem Informasi untuk pemantauan penjualan berbasis website sehingga, sistem usulan ini akan memperjelas pembagian pekerjaan pada organisasi yang ada, yang dimana dalam pembuatan rencana penjualan dapat dilakukan bukan hanya pada G.M TPR tetapi G.M TPM, dan G.M Key Account juga berperan dalam pembuatan rencana penjualan. Dengan cara ini proses pemantauan penjualan dapat lebih terpantau sehingga lebih efektif dan efisien. Sistem ini tentunya terintegrasi pada data yang dapat menghasilkan proses pemantauan penjualan, pembuatan rencana penjualan dan laporan pendapatan yang cepat dan akurat.

\section{Use Case Diagram}

Pada gambar di bawah ini yaitu Use Case Diagram Rancangan Sistem Informasi pemantauan penjualan berbasis website yang menggambarkan alur sistem dengan use case dan aktor yang terlibat : 
ISSN : $2356-5195$

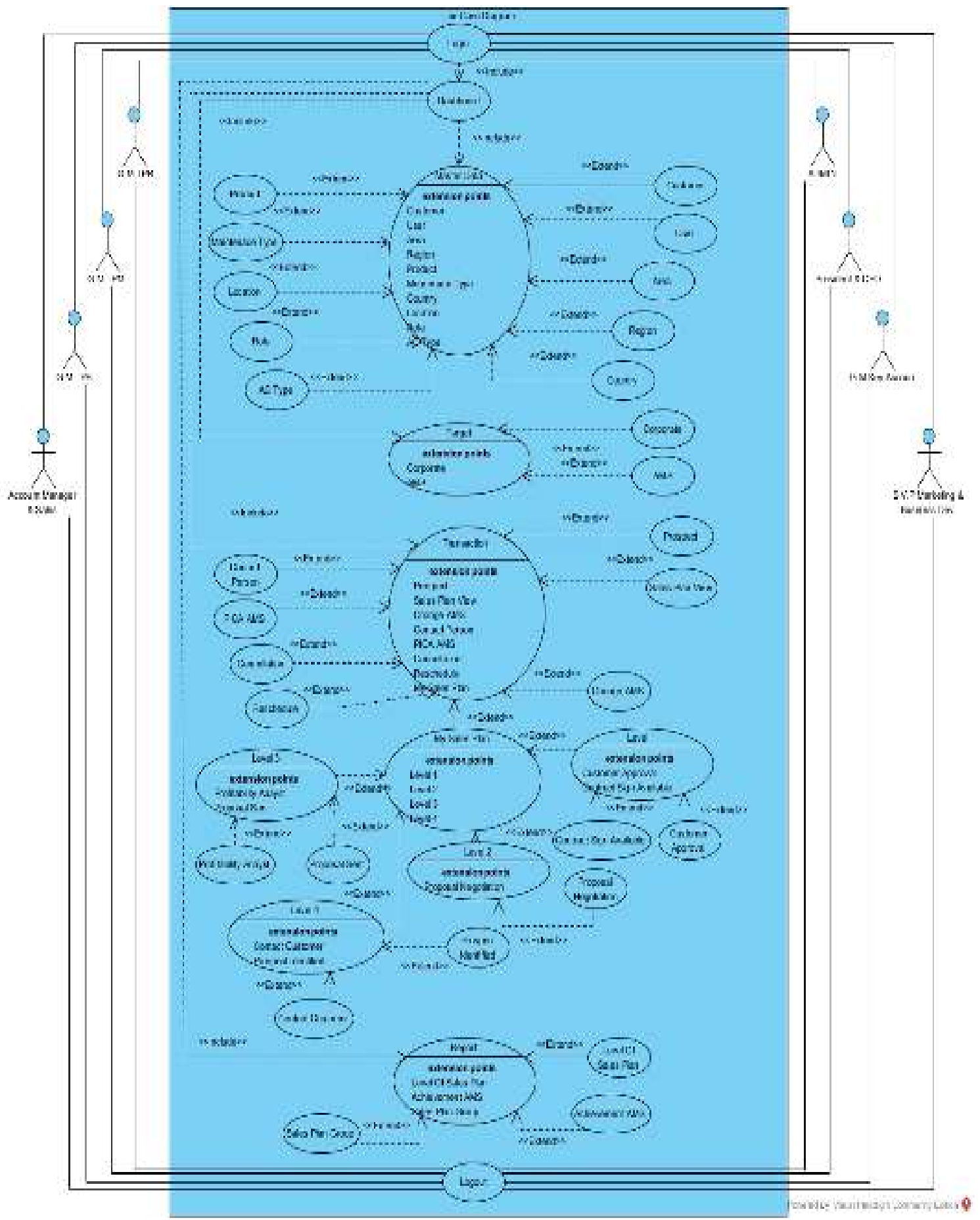

Gambar 3. Use Case diagram rancangan Sistem Informasi pemantauan penjualan

Dari diagram di atas, terdapat 1 (satu) sistem yang mencakup seluruh kegiatan dalam proses penginputan, 8 (delapan) actor yang melakukan kegiatan yaitu President \& CEO, S.V.P Marketing \& Business Development, G.M TPR, G.M TPM, G.M TPB Account Manager \& Sales, ara G.M Key Account dan Admin dan terdapat 31 use case yang akan dilakukan oleh aktor tersebut. Serta terdapat 9 extends yaitu master data, transaction, my sales plan, target, level 1, level 2, level 3, level 4 dan report. 


\section{Class Diagram}

Class diagram sangat membantu dalam visualisasi kelas dari suatu sistem yang dibuat karena class diagram adalah deskripsi kelompok objek dengan atribut (property) dan relasi yang sama pada sebuah basis data. Selain itu class diagram dapat memberikan pandangan global atas sebuah sistem yang di buat. Berikut class diagram Sistem Informasi pemantauan penjualan berbasis website:
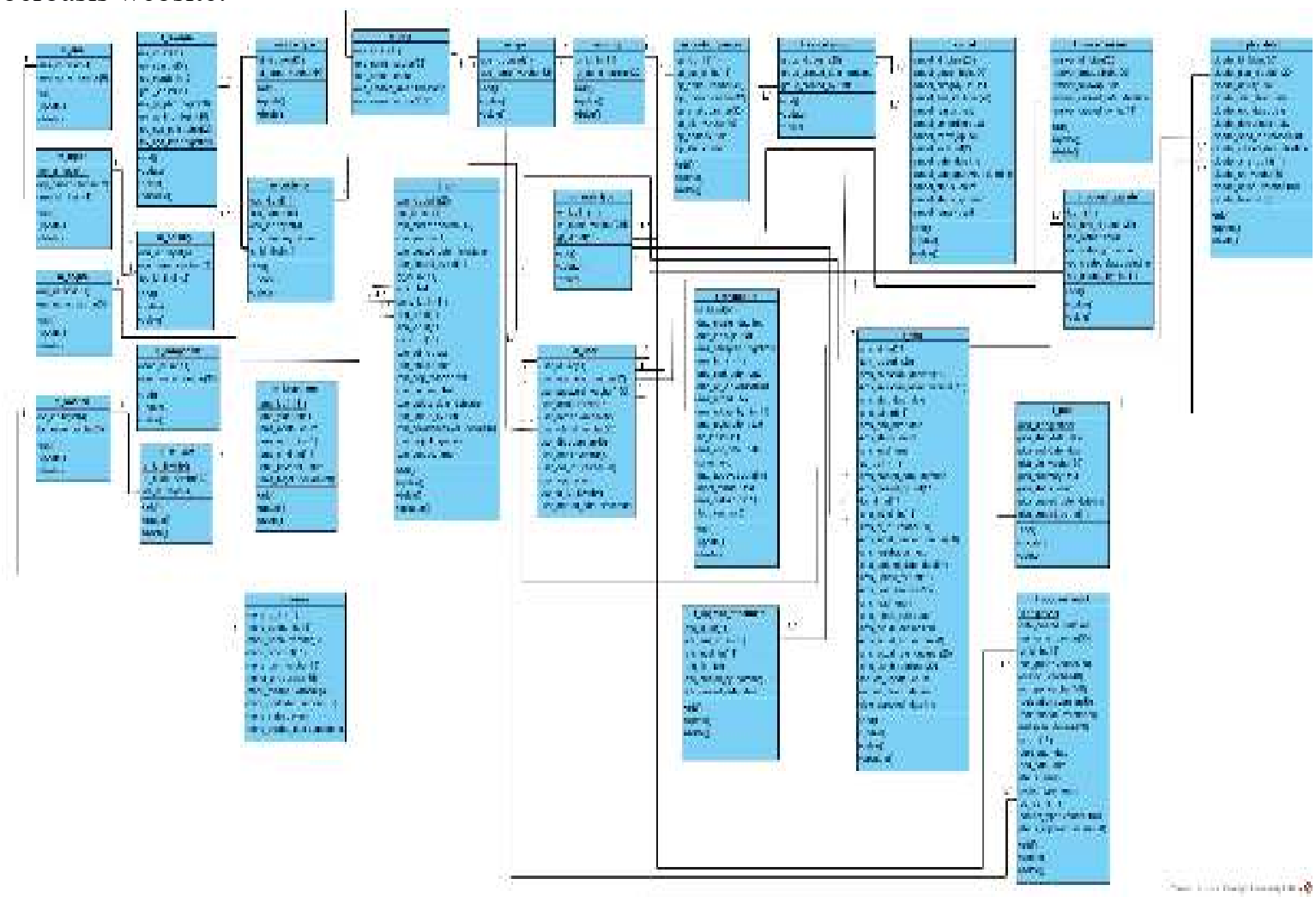

Gambar 4. Class Diagram rancangan Sistem Informasi Surat Pengantar

Class Diagram Rancangan Sistem Informasi pemantauan penjualan yang menggambarkan rancangan basis data yang akan digunakan pada sistem.

\section{Tampilan Rancangan Sistem}

Dibawah ini adalah tampilan rancangan sistem informasi pemantauan penjualan :

1. Tampilan Halaman Login

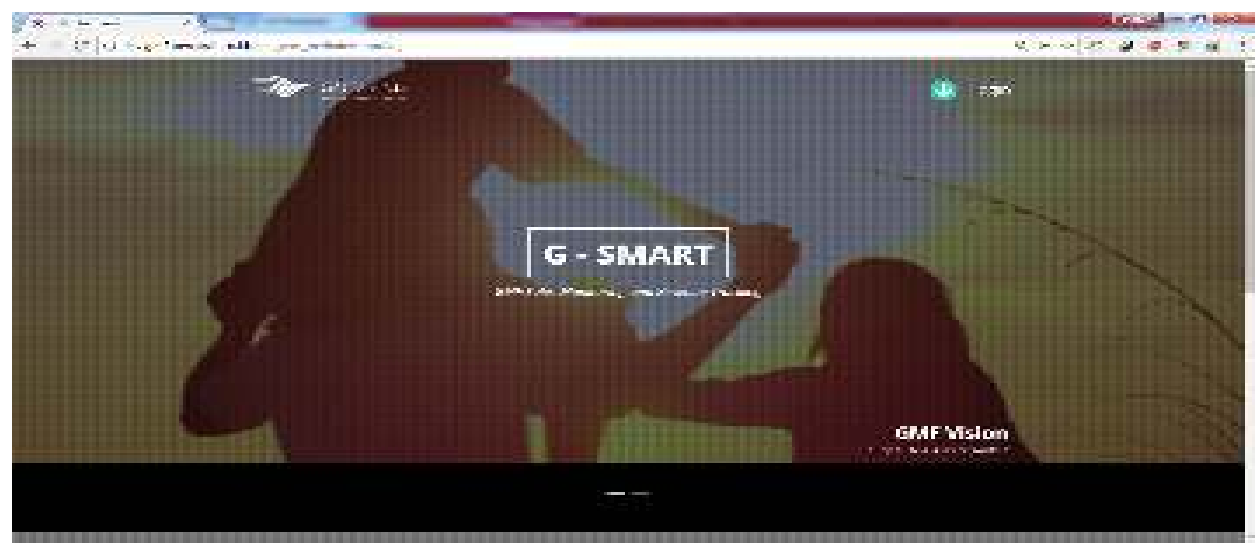

Gambar 5. Tampilan halaman Login 
Tampilan diatas adalah tampilan awal sebelum masuk kedalam sistem informasi pemantauan penjualan, setiap user harus melakukan login dengan memasukan username dan password yang benar agar dapat masuk kedalam sistem.

2. Tampilan Halaman Dashboard

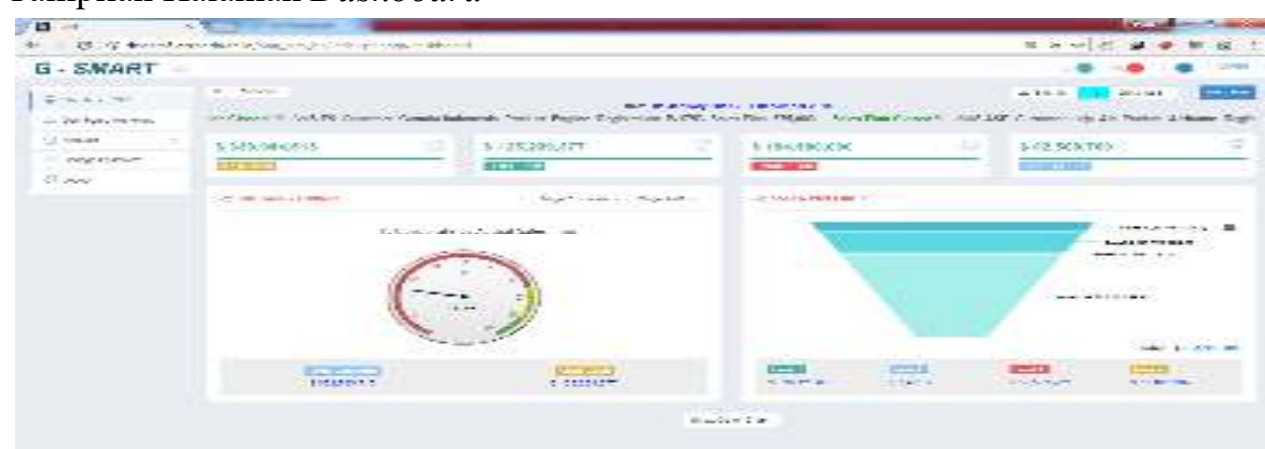

Gambar 6. Tampilan halaman Dashboard

Setelah user melakukan proses login dengan benar, maka akan tampil dashboard yang mana didalamnya menggambarkan nilai setiap transaksi yang ada, dapat melihat nilai dan detail data, ketika klik salah satu grafik yang ada.

3. Tampilan Halaman Prospect

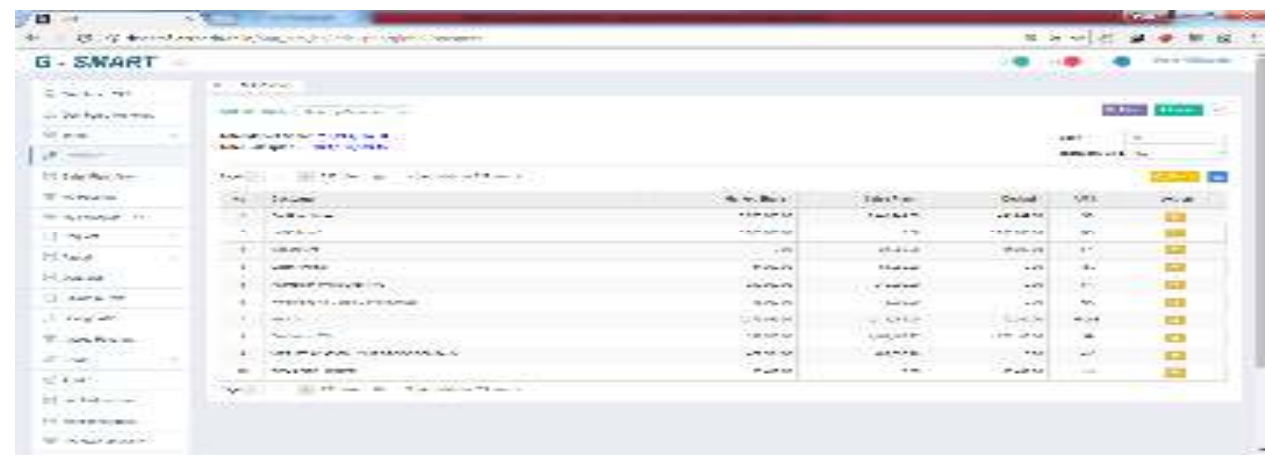

Gambar 7. Tampilan halaman Prospect

Tampilan dari halaman Prospect yang mana menyajikan halaman yang didalamnya terdapat data yang telah dilakukan input transaksi. Dihalaman ini, user dapat melakukan tambah , edit, hapus dan ekport data kedalam bentuk Excel.

4. Tampilan Halaman Request Upgrade

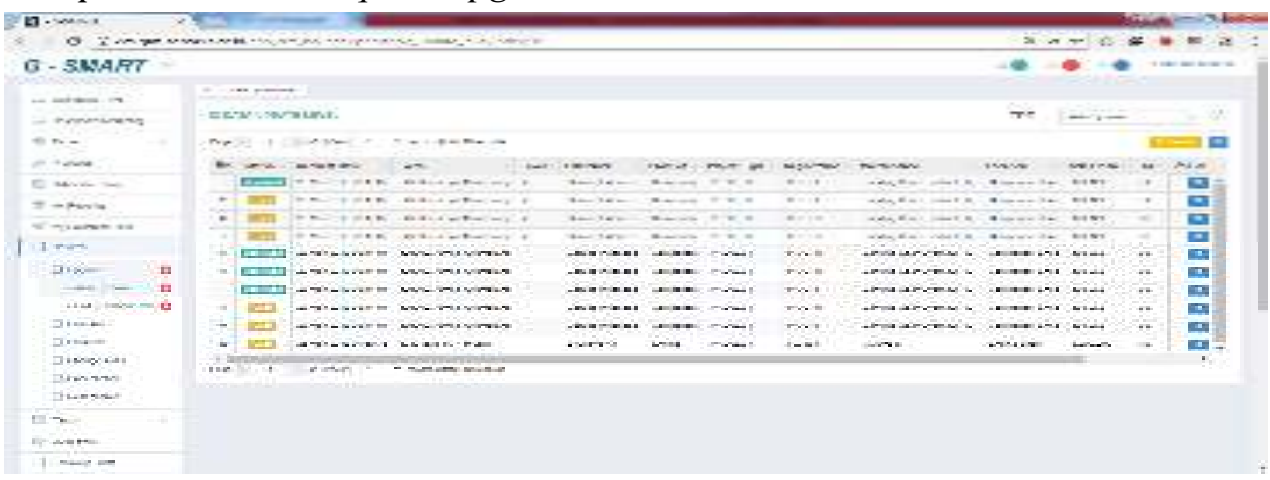

Gambar 8. Tampilan halaman Request Upgrade

Tampilan diatas adalah tampilan halaman request upgrade yang berfungsi untuk menerima request upgrade dari setiap Account Manager \& Sales dan Para G.M Key Account. 
5. Tampilan Halaman PICA

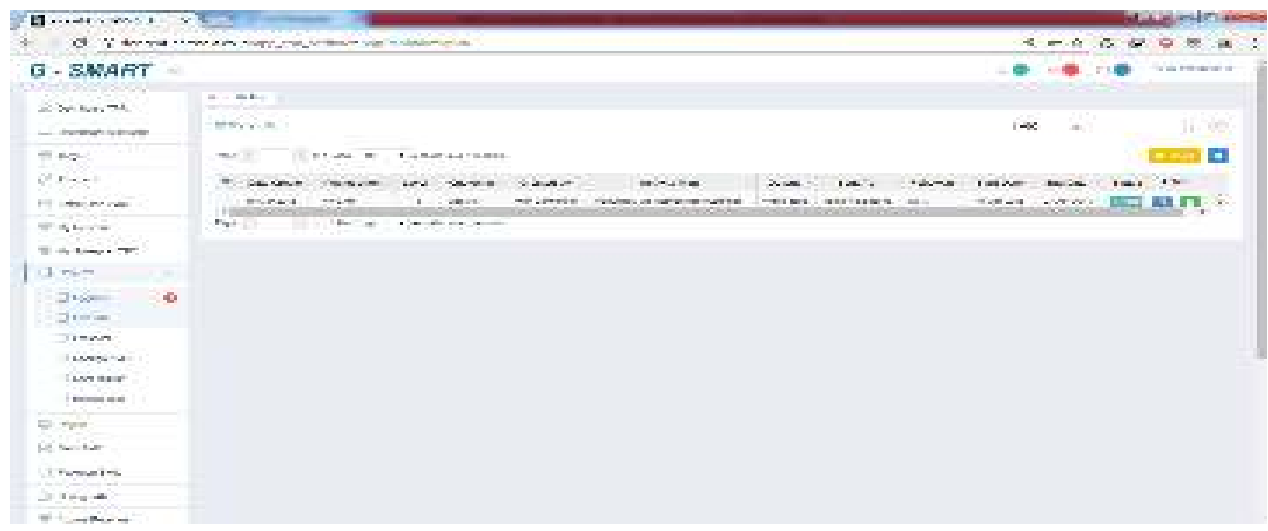

Gambar 9. Tampilan halaman PICA

Tampilan diatas adalah halaman PICA yang dikirim oleh setiap data yang ada dan dapat diakses oleh G.M TPR, Account Manager \& Sales dan para G.M Key Account.

6. Tampilan Halaman Reschedule

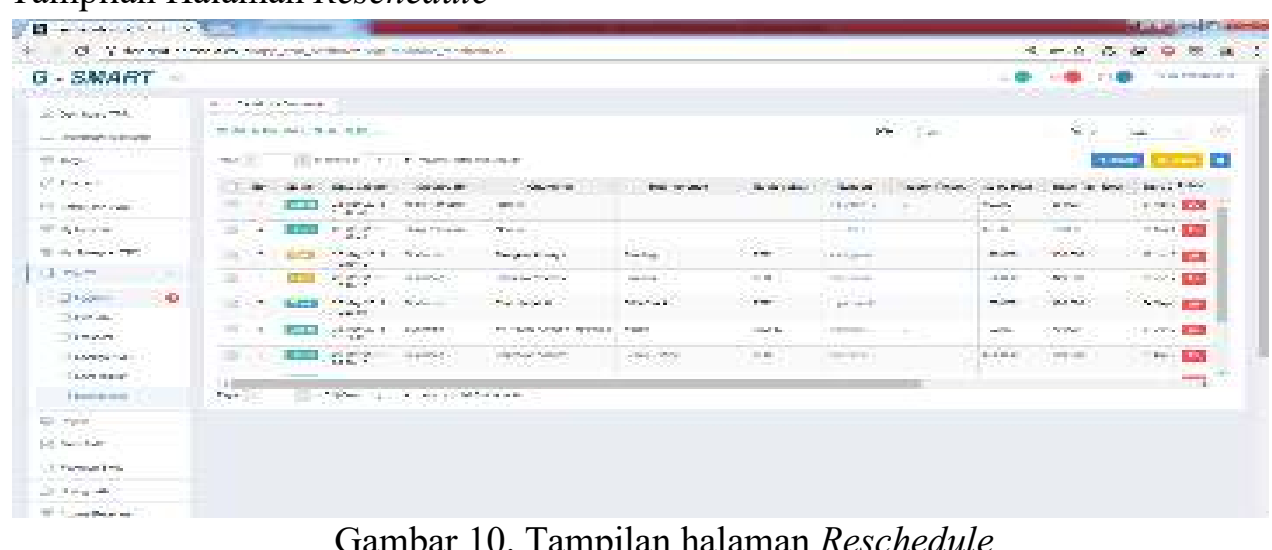

Gambar 10. Tampilan halaman Reschedule

Pada tampilan ini adalah tampilan reschedule dari data yang ada dan dapat diakses oleh G.M TPR, Account Manager \& Sales dan para G.M Key Account.

7. Tampilan Halaman Report Sales Plan Group

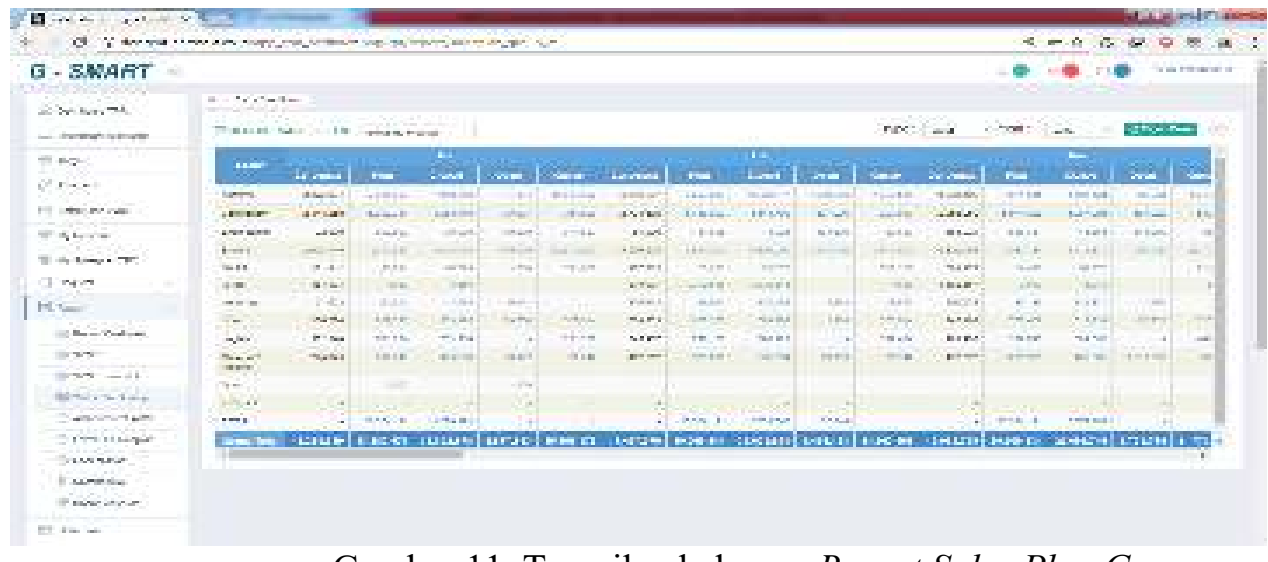

Gambar 11. Tampilan halaman Report Sales Plan Group

Pada tampilan ini adalah tampilan halaman report sales plan group yang dibuat dari setiap transaksi yang ada pada halaman ini juga bisa export ke excel. 
8. Tampilan Halaman Report Achievment AMS

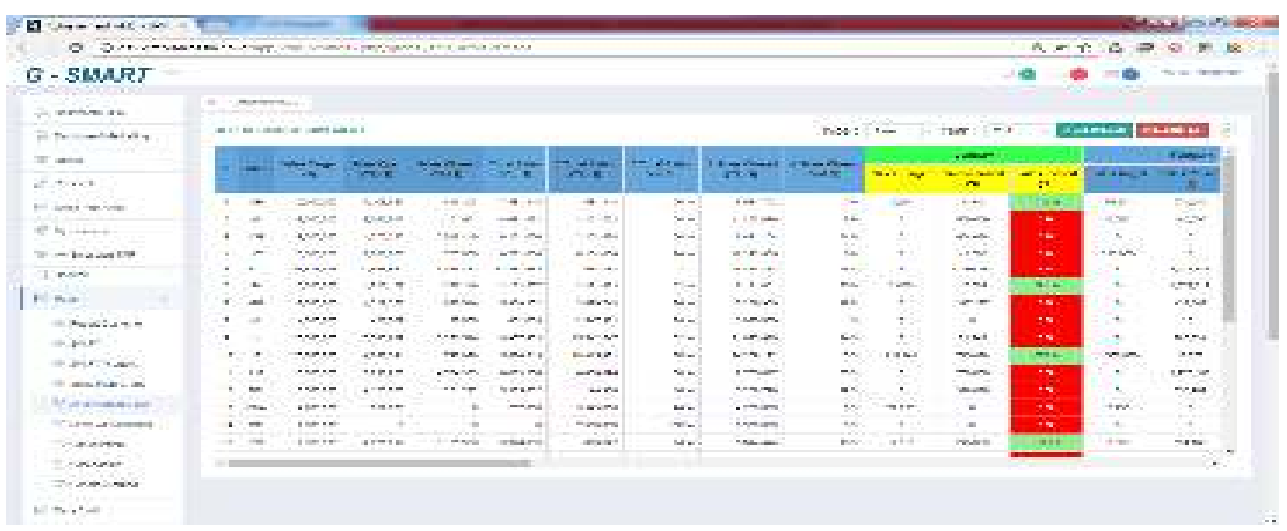

Gambar 12. Tampilan halaman Report Achievment AMS

Pada tampilan ini adalah tampilan halaman report achievment Account Manager \& Sales dan Para G.M Key Account. Report dibuat berdasarkan setiap transaksi yang ada dan dapat export ke excel.

9. Tampilan Halaman Report Level Of Sales Plan

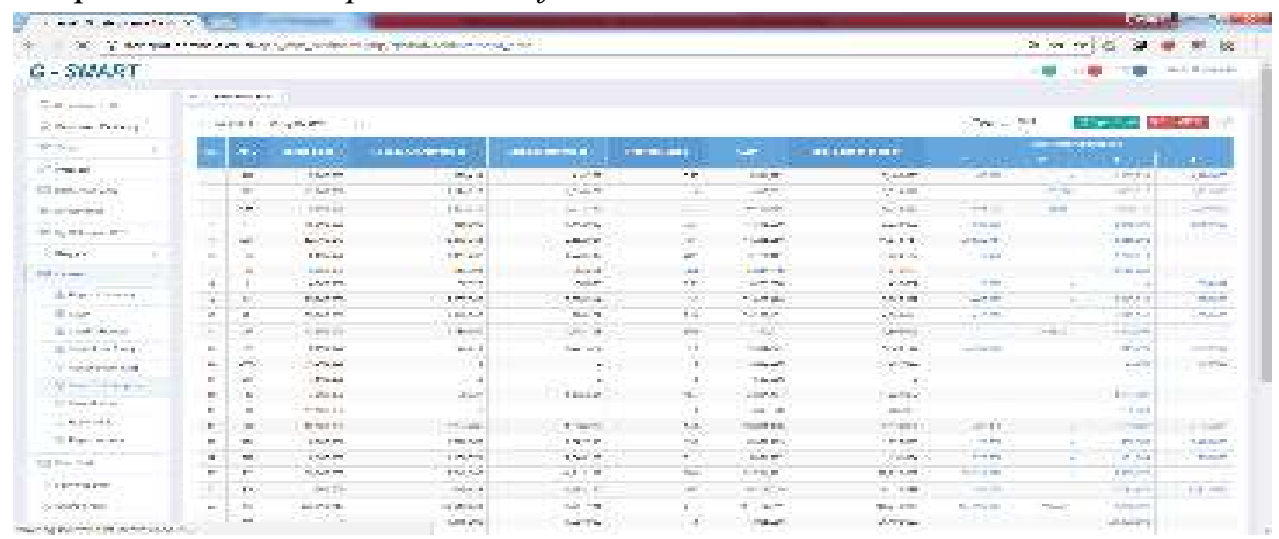

Gambar 13. Tampilan halaman Report Level Of Sales Plan

Pada tampilan ini adalah tampilan halaman report level of sales plan yang dibuat berdasarkan transaksi yang ada pada report ini dapat di export ke excel.

10. Tampilan Halaman My Sales Plan

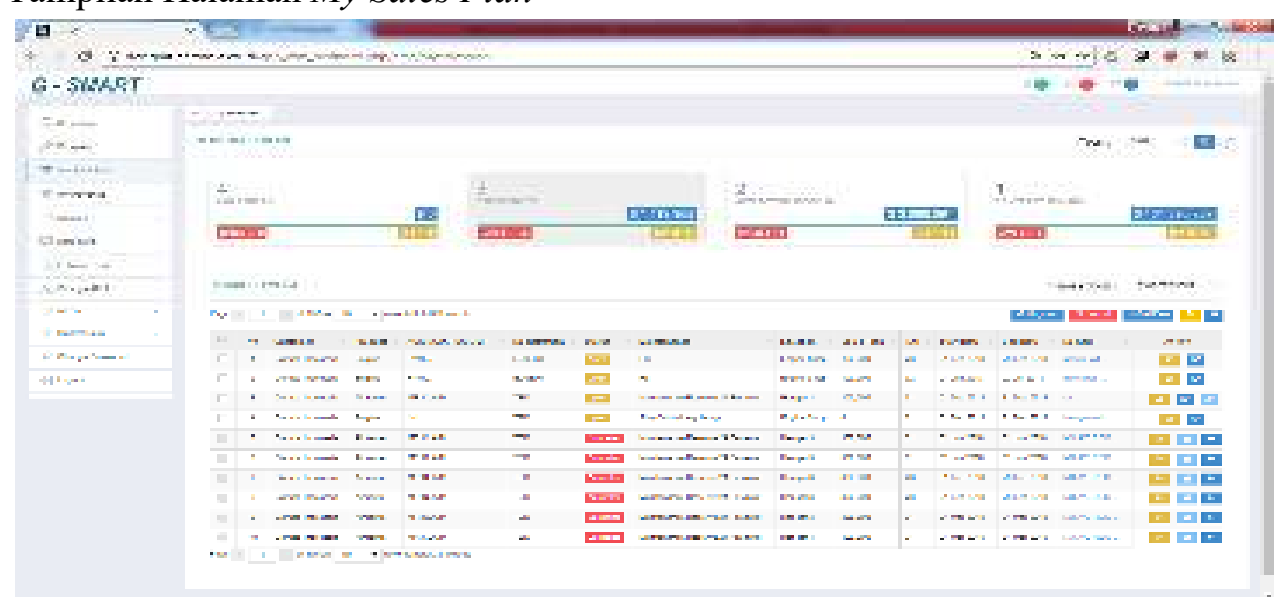

Gambar 14. Tampilan halaman My Sales Plan

Halaman my sales plan pada halaman ini digunakan untuk setiap Account Manager $\&$ Sales dan para G.M Key Account untuk membuat PICA, upgrade level, cancel data yang ada. 
ISSN : $2356-5195$

Online ISSN: 2654 - 8704

11.Tampilan Halaman Form Upgrade Level

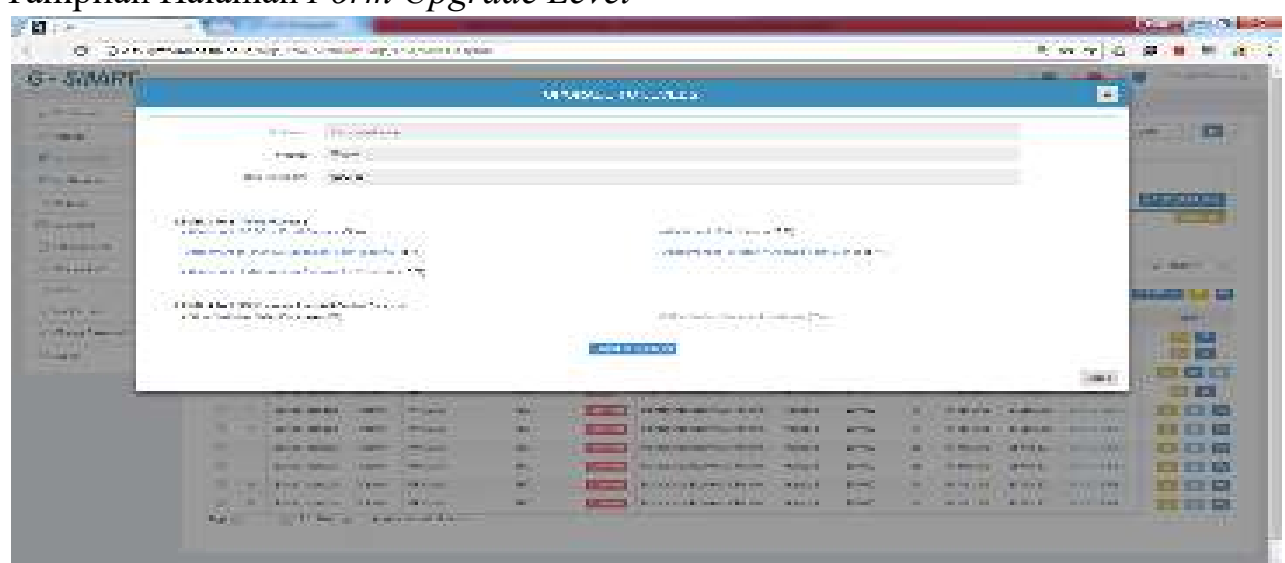

Gambar 15. Tampilan halaman Form Upgrade Level

Halaman upgrade level yang dimana setiap Account Manager \& Sales dan para G.M Key Account harus memenuhi sesuai kriteria setiap level dan akan di terima oleh G.M TPR.

12.Tampilan Halaman Form Cancellation

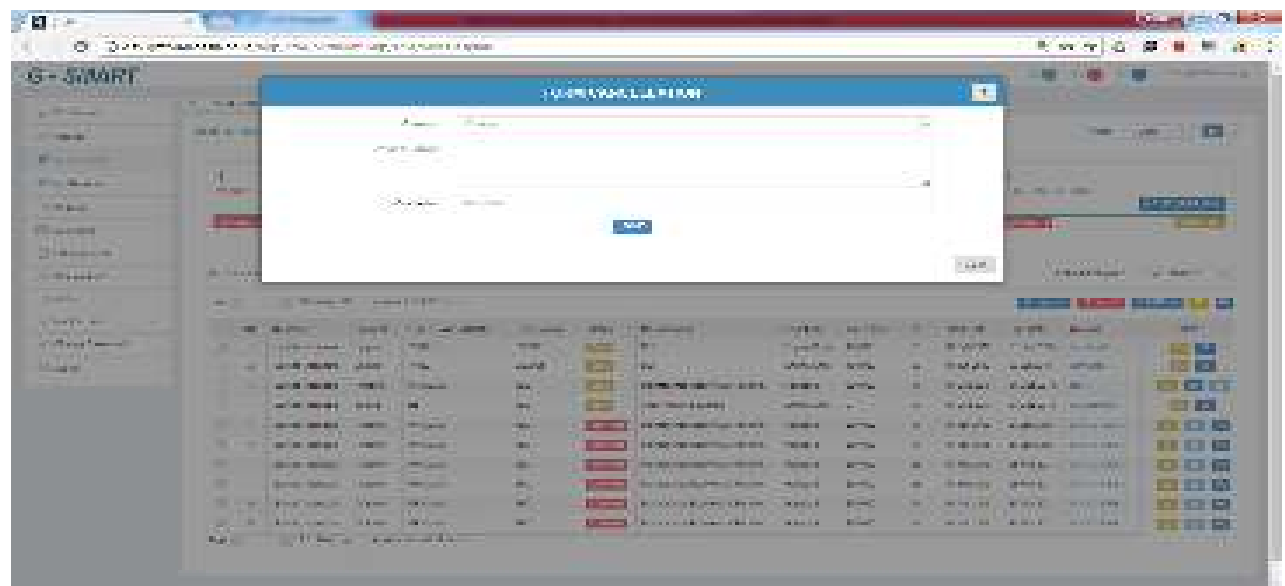

Gambar 16. Tampilan halaman Form Cancellation

Pada tampilan ini adalah tampilan form cancellation digunakan untuk meng cancel data yang ada.

13.Tampilan Halaman Form PICA

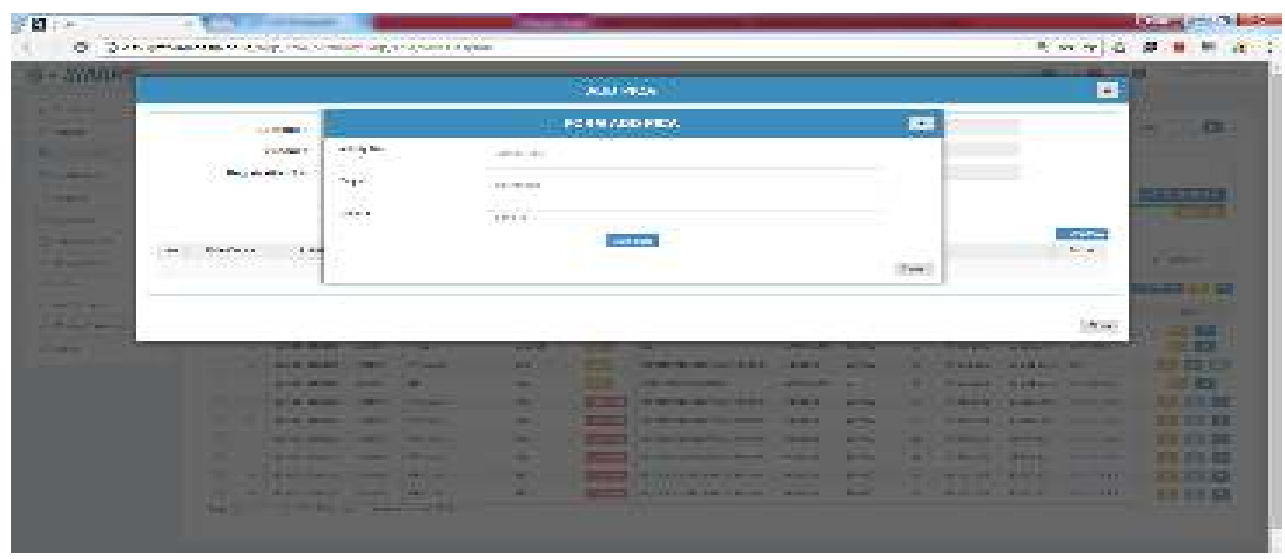

Gambar 17. Tampilan halaman Forn PICA

Pada halaman form pica ini untuk membuat pica yang dilakukan Account Manager \& Sales dan para G.M Key Account. 


\section{KESIMPULAN}

Sistem informasi pemantauan penjualan pada PT. GMF Aero Asia memiliki manfaat untuk sistem pembagian pekerjaan dalam organisasi pada PT. GMF Aero Asia yaitu unit Marketing \& Business Development lebih jelas, lebih baik lagi dan dapat menghasilkan laporan pendapatan yang lebih baik secara otomatis oleh sistem usulan yang dibuat. Laporan pendapatan yang dihasilkan adalah Sales Plan Group, Level Of Sales Plan dan Achievment AMS.

\section{SARAN}

Dalam bahasan ini memuat saran untuk dilakukan pengembangan agar menjadi sistem yang lebih baik lagi dan meminimalisir kemungkinan terjadinya error atau defect yang tentunya dapat mengakibatkan kerugian bagi penggunanya.

\section{DAFTAR PUSTAKA}

[1] Abdullah, Thamrin dan Francis Tantri. 2016. Manajemen Pemasaran. Depok : PT Raja Grafindo Persada.

[2] B. Romney, Marshal dan Paul John Steinbart. 2014. Sistem Informasi Akuntansi, Edisi ketigabelas, Diterjemahkan oleh : Kikin Sakinah, Nur Safira, dan Novita Puspitasari. Jakarta: Salemba Empat.

[3] Dr. Eman Suherman, S.E., M.Pd. 2015 . Praktik Bisnis Berbasis Entrepreneurship.

[4] Dr.H.A. Rusdiana, M., \& Moch. Irfan, S. M. 2014. Sistem Informasi Manajemen.Bandung: Pustaka Setia.

[5] Rosa. M. Shalahuddin. 2013. Modul Pembelajaran Rekayasa Piranti Lunak. Bandung: Modula. 